\title{
Revised Paper
}

\section{A Paradigm Shrift-}

\section{Autonomous Changes in the Concentration of Water Vapor,}

\author{
Alone, Drive Climate Change \\ William A. Van Brunt ${ }^{1 *}$ \\ ${ }^{1}$ CEO, JFA, LLC, Wayzata, Minnesota, USA \\ ${ }^{*}$ William A. Van Brunt, CEO, JFA, LLC, Wayzata, Minnesota, USA
}

Received: November 2, 2020 Accepted: November 20, 2020 Online Published: November 23, 2020

doi:10.22158/se.v5n4p22 URL: http://dx.doi.org/10.22158/se.v5n4p22

\begin{abstract}
Changes in average global temperature are not driven by changes in the concentration of carbon dioxide. Instead, autonomous changes in the average global concentration of water vapor resulting from differences in average global precipitation and evaporation drive changes in water vapor heating. The average accuracy of average global temperature changes determined solely on the basis of changes in the concentration of average global water vapor in accordance with Eqn. 3 when compared to the variable annual, 1880-2019, temperature record is $99.86 \%$. Changes in the concentration of water vapor and changes in water vapor heating are not a feedback response to changes in the concentration of $\mathrm{CO}_{2}$. Rather recent increases in the average global temperature have resulted from increases in the concentration of water vapor and increases in water vapor heating driving each other in an autonomous positive feedback loop. This feedback loop and thus global warming, can be brought to a halt if the average global rate of precipitation can be brought into balance with the average global rate of evaporation and maintained there. Moreover, the recent increases in average global temperature since 1976 can be reversed, reduced by $1{ }^{\circ} \mathrm{C}$, if average global precipitation can be increased by $0.3 \%$ of the average annual rate of global precipitation.
\end{abstract}

\section{Introduction}

Until I attended the celebration of the award of the Nobel Peace Prize to the Intergovernmental Panel on Climate Change and Al Gore in 2007 in Oslo for their work on global warming, I was convinced that global warming was the result of the continuing increase in atmospheric $\mathrm{CO}_{2}$.

However, at this celebration in 2007 , I came away believing that the claim that global warming was the 
result of the continuing increase in atmospheric $\mathrm{CO}_{2}$, was, at best, questionable and even if true, the proposed experiment of limiting carbon emissions, ludicrous, because, if $\mathrm{CO}_{2}$ had the effects claimed, given its persistence in the atmosphere, there being no practical means of reducing the concentration of $\mathrm{CO}_{2}$ in the atmosphere (See Shaw, J. Controlling the Global Thermostat, NOVEMBER-DECEMBER 2020 Harvard Magazine-“"A thousand years from now......more than half the heat-trapping carbon-dioxide that humanity has pumped into the atmosphere since the beginning of the Industrial Revolution will still be there.") limiting the rate of growth of carbon emissions, could at best slow the rate of global warming while the ever warming seas released $\mathrm{CO}_{2}$ at increasing rates and absorbed atmospheric $\mathrm{CO}_{2}$ at decreasing rates and the potential for the problem to become increasingly serious, as time passed, remained.

More importantly, I have since determined that the data clearly shows that it is the increasing concentration of water vapor, the primary greenhouse gas, not $\mathrm{CO}_{2}$, that is driving global warming.

Therefore, in the interest of my grandchildren, I have embarked on a journey to bring the true cause to light and urge, irrespective of the proposed and incongruous $\mathrm{CO}_{2}$ experiment, that efforts to drive a slight increase in average precipitation be undertaken.

The results of my efforts since 2007 and all underlying data and references are set out in my paper on this subject entitled "Autonomous Changes in the Concentration of Water Vapor Drive Climate Change" which was published in August in Atmospheric and Climate Sciences, https://www.scirp.org/pdf/acs_2020082016073298.pdf. Given the questions that are likely to arise, this paper is comprehensive, 65 pages in length.

To increase dissemination of this wholly novel and critical finding, a shorter, conclusory summary follows. The new principles of atmospheric physics underlying this work are set out and are summarized in the Appendix.

\section{Principal Conclusions}

Shown in Figure 1 are computed percentage changes, since 1880, in the average global concentration (average evaporation less average precipitation) of water vapor, TPW, the dominant greenhouse gas, the average concentration of which is seven times greater than $\mathrm{CO}_{2}$. 


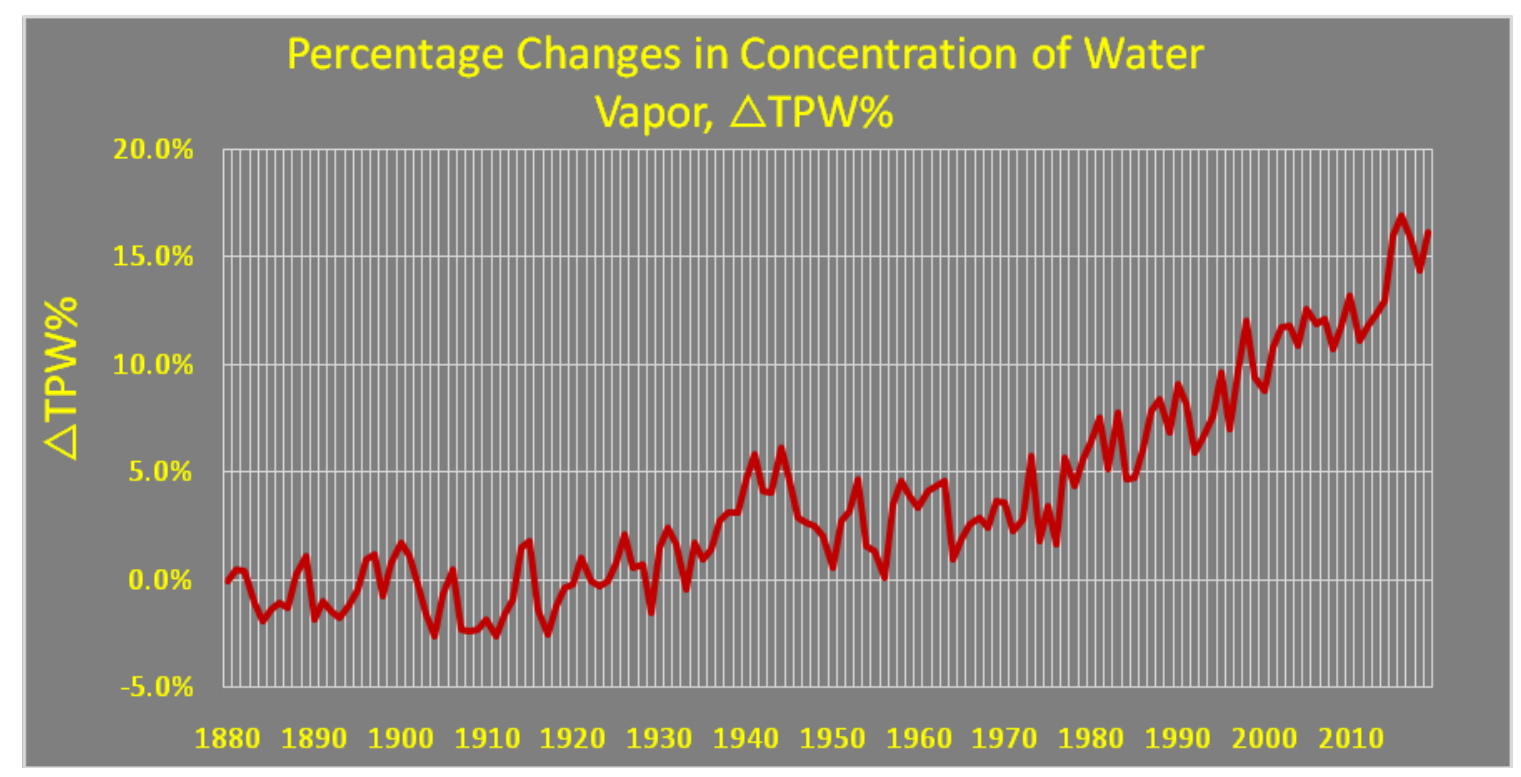

Figure 1. Percentage Changes in Concentration of Water Vapor[1]

The data shows that, since 1976 , the period of the recent $1^{\circ} \mathrm{C}$ increase in average global temperature, the concentration of water vapor, the primary greenhouse gas, has increased by $\sim 12 \%$ and in terms of ppmv, has been increasing at a rate four times greater than $\mathrm{CO}_{2}$.

Notwithstanding this, the current paradigm is that the increasing concentration of $\mathrm{CO}_{2}$ is THE cause of global warming.

The Problem that is Global Warming-Shown in Figure 2 are the percentage changes in average global temperature, $\Delta \mathrm{T}_{\text {Avg }}$, between 1880 and 2019 .

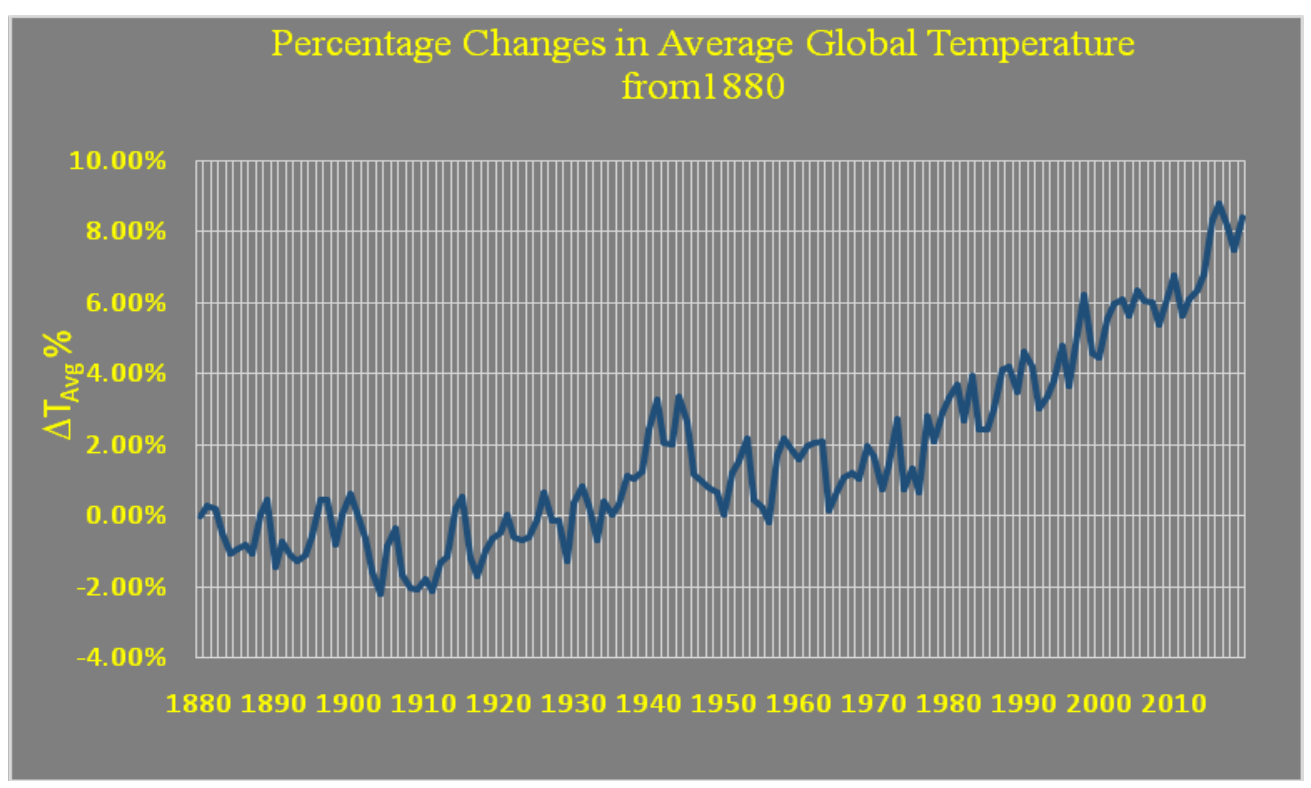

Figure 2. Percentage Changes in Average Global Temperature 
In the last 40 years, the average global temperature, measured in degrees Celsius, has increased by nearly $8 \%$, a $0.25^{\circ} \mathrm{C}\left(0.45^{\circ} \mathrm{F}\right)$ per decade increase.

That Global Warming is a transcendent and presumably ever growing, global problem, which, if unchecked, poses an existential risk and that there is real exigency in dealing with this, is beyond debate.

\section{"Unless the Cause is Understood, a Problem Cannot be Solved." Naoto Kan}

The cause of this exigent problem must be understood and quickly addressed. The potential consequences of the ever increasing average global temperature are becoming increasingly dire, potentially posing an existential and, for some factors, a possibly irreversible risk.

Given that year to year changes variations in annual average solar radiation are inconsequential it is clear that the temperature changes shown in Figure 2 are driven by changes in heating from the greenhouse gases, GHG and to a small degree, changes in average annual cloud albedo. For purposes of these calculations it is assumed that the year to year average variability in cloud albedo correlate with changes in the concentration of water vapor and the slight effects of these changes on average global temperature are captured by Eqn. 3.

\section{The Cause-The Continuing Increase in the Concentration of Water Vapor}

Set out in Figure 3 is a comparison from 1880 of the percentage changes in average global temperature, $\Delta \mathrm{T}_{\mathrm{Avg}}$, gauged against the left vertical axis and percentage changes in the concentration of water vapor, $\Delta \mathrm{TPW}$, on the right.

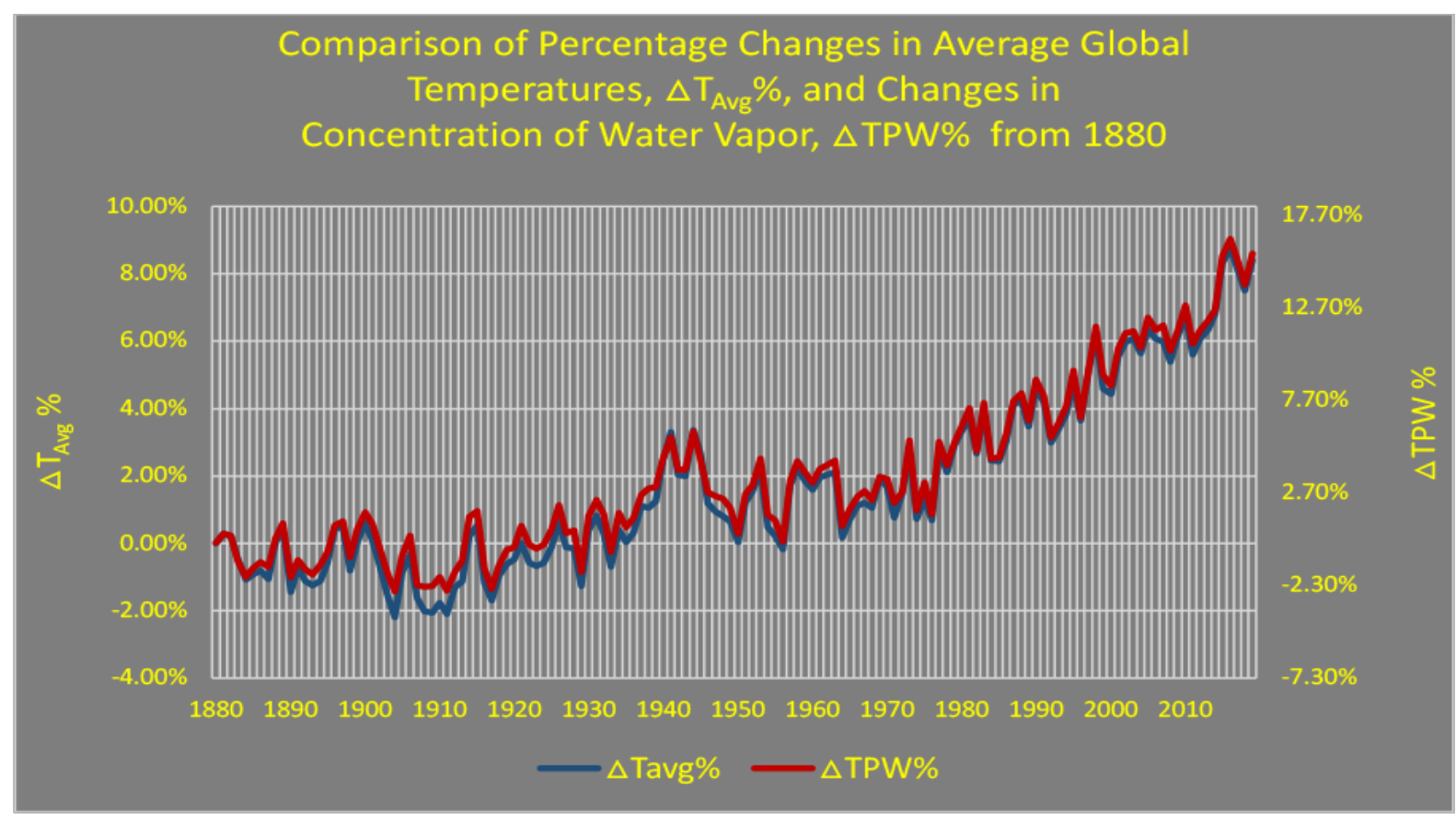

Figure 3. Percentage Changes in Average Global Temperature and the Concentration of Water Vapor, $\triangle$ TPW 
With a correlation coefficient of 0.997 , it is clear that it is changes in the concentration of water vapor, the dominant greenhouse gas, not $\mathrm{CO}_{2}$, that is driving climate change.

The Solution-Reducing the Concentration of Water Vapor by Slightly Increasing Average Global Precipitation

The solution lies in increasing average global precipitation, slightly, relative to the rate of evaporation, which is what occurs naturally when there is a Year over Year (YoY) reduction in average global temperature. It is, therefore, imperative that environmentally sound, practical, efficient and effective means are found and quickly put into place to bring the rate of the increase in average global temperature to zero and to slowly bring the average global temperature down by $1^{\circ} \mathrm{C}$, to return to the temperatures of the mid 1970s. Slight increases in the rate of average global precipitation (perhaps through increasing the concentration of cloud condensing nuclei in the proper locations, manner and at the appropriate times) until it reaches $0.3 \%$ of the average annual rate of precipitation and thereafter maintained in equivalence with evaporation, would eliminate this increase.

\section{Reducing or Limiting Carbon Emissions, the $\mathrm{CO}_{2}$ Experiment}

Given the role of water vapor, why ever would one propose solution focused on only one factor, limiting $\mathrm{CO}_{2}$ emissions, when no one can predict with any certainty, what, if any, benefit limiting carbon emissions might effect. Therefore, this effort is no more than an experiment, an experiment, destined to fail. This is akin to attempting to reduce Night Air to stop the black plague while ignoring rodent infestation.

Where else in science, when faced with multiple, possible causation factors, does one seek to find a solution by assuming only one is the cause and seeking to control only that factor, and, at that, an immeasurable contributor. Like eliminating Night Air could not stop the plague, reducing carbon emissions cannot stop global warming.

The results of this experiment will take decades to determine. If the concentration of water vapor and, therefore, the average global temperature continue to increase, the world will be at an ever increasing risk. This is incogitable.

If $\mathrm{CO}_{2}$ were THE Cause, THE Driver of Climate Change, after several decades of research and the expenditure of tens of millions of dollars, when compared to the average annual global temperature record from 1880, published climate models posited on this assumption should accurately replicate the significant variability in the annual temperature record. Why is that they do not? 


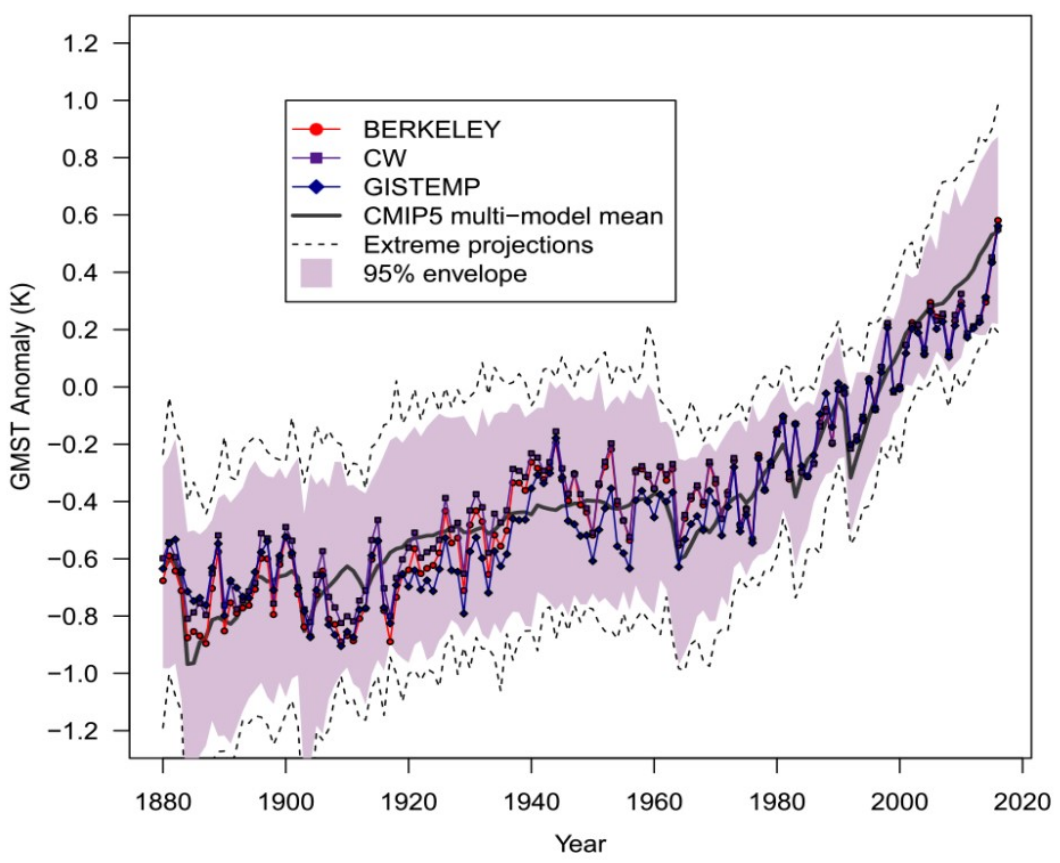

Figure 4. Typical Results of Computer Models of Changes in Average Global Temperature

For each year, the average global surface temperature is at the temperature the average net absorbed heating (total heating less the power driving evaporation and thermal convection) can drive.

Referring to Figure 4, a number of these " $\mathrm{CO}_{2}$ " models calculate annual average global temperatures measurably greater than actual. For the modeled surface temperature to exceed the actual surface temperature would require the IR radiation emitted by the surface to exceed the actual net absorbed heating in violation of the first law of thermodynamics. Thus, the theories underlying models that return such results are facially incorrect. In addition, many individual models show a YoY increase in temperature when, for that year, the temperature declined. Finally, no published model tracks even the 10 largest year to year variations in average global temperature. These hindsight comparisons illustrate the failings of these models.

Shown in Figure 5, is the record of changes in total heating, shown in dark blue, and the theoretical maximum change in heating that could have resulted from changes in the concentration of $\mathrm{CO}_{2}$, shown in red, based upon the expression that changes in heating resulting from changes in the concentration of $\mathrm{CO}_{2}, \Delta \mathrm{TH}_{\mathrm{CO} 2}$, are determined as:

\section{$\Delta \mathrm{TH}_{\mathrm{CO} 2}=5.35 \ln \left(\mathrm{C} / \mathrm{C}_{\mathrm{o}}\right)$}

Where $\mathrm{C}$ is the atmospheric concentration of $\mathrm{CO}_{2}$ 


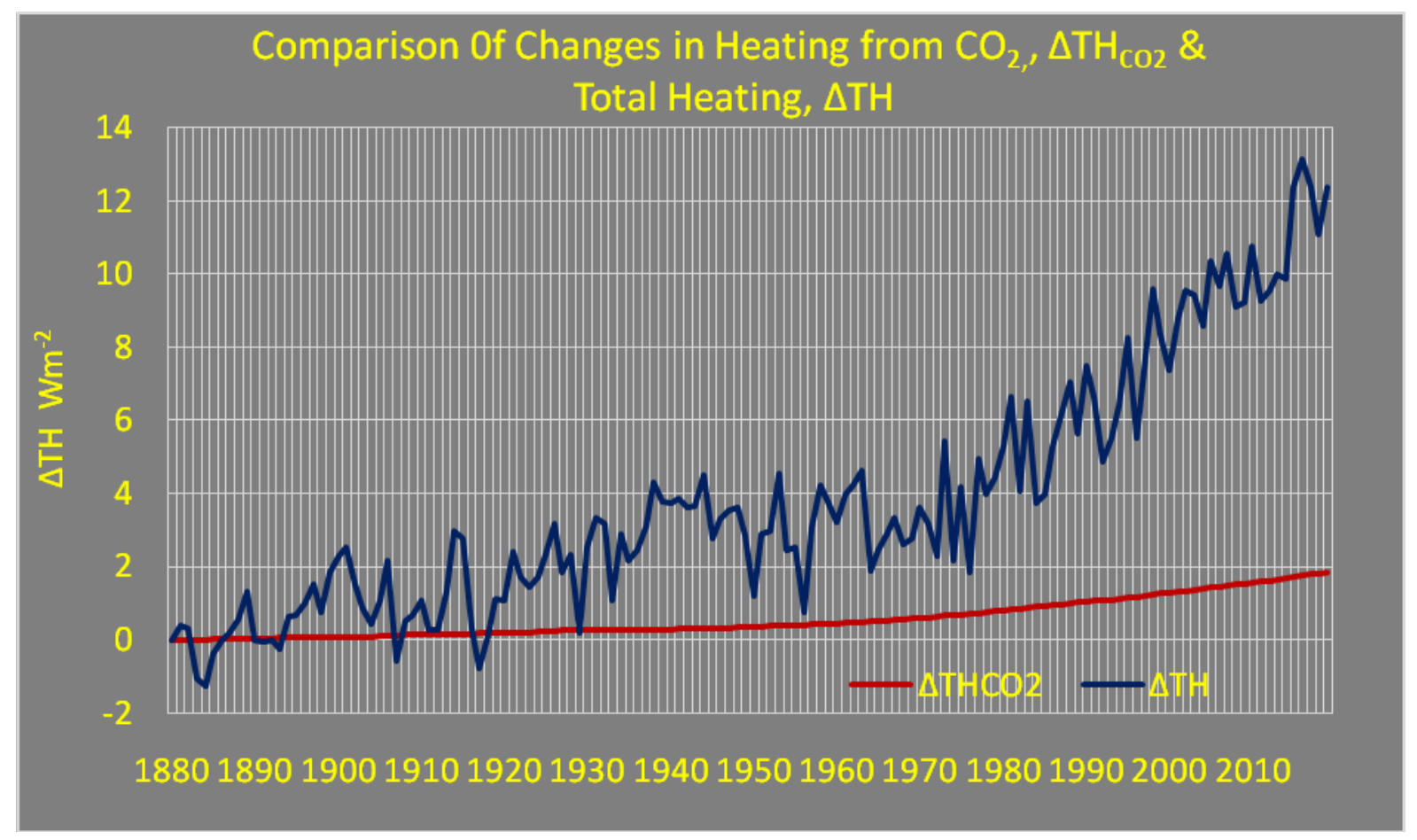

Figure 5. Changes in Total Heating $\triangle T$ TH Shown in Dark Blue and the Maximum Change in Heating, $\Delta \mathrm{TH}_{\mathrm{CO} 2}$, from Changes in the Concentration $\mathrm{CO}_{2}$, Shown in Red Could Drive, for the Period, 1880-2019, $\mathrm{Wm}^{-2}$

Clearly $\mathrm{CO}_{2}$, itself, cannot have even theoretically driven global warming. Moreover, the changes in heating shown as $\Delta \mathrm{TH}_{\mathrm{CO} 2}$ in Figure 5 is referred to as the "theoretical" maximum change, because there is no proof that, as a component of the atmosphere, this is correct and, in fact, this work shows that the heating contributed by increases in the concentration of $\mathrm{CO}_{2}$ since 1880 is imperceptible.

If $\mathrm{CO}_{2}$ is thought to be THE Driver of Climate Change as a Forcing Mechanism Driving Feedback Increases in Heating, why is it, that, between 1880 and 2019, except for the period 1901-03, while the theoretical YoY heating from $\mathrm{CO}_{2}$ increased as shown in Figure 5, changes in YoY total heating were unrelated and $40 \%$ of the YoY changes in total heating were reductions? See Figure 6. 


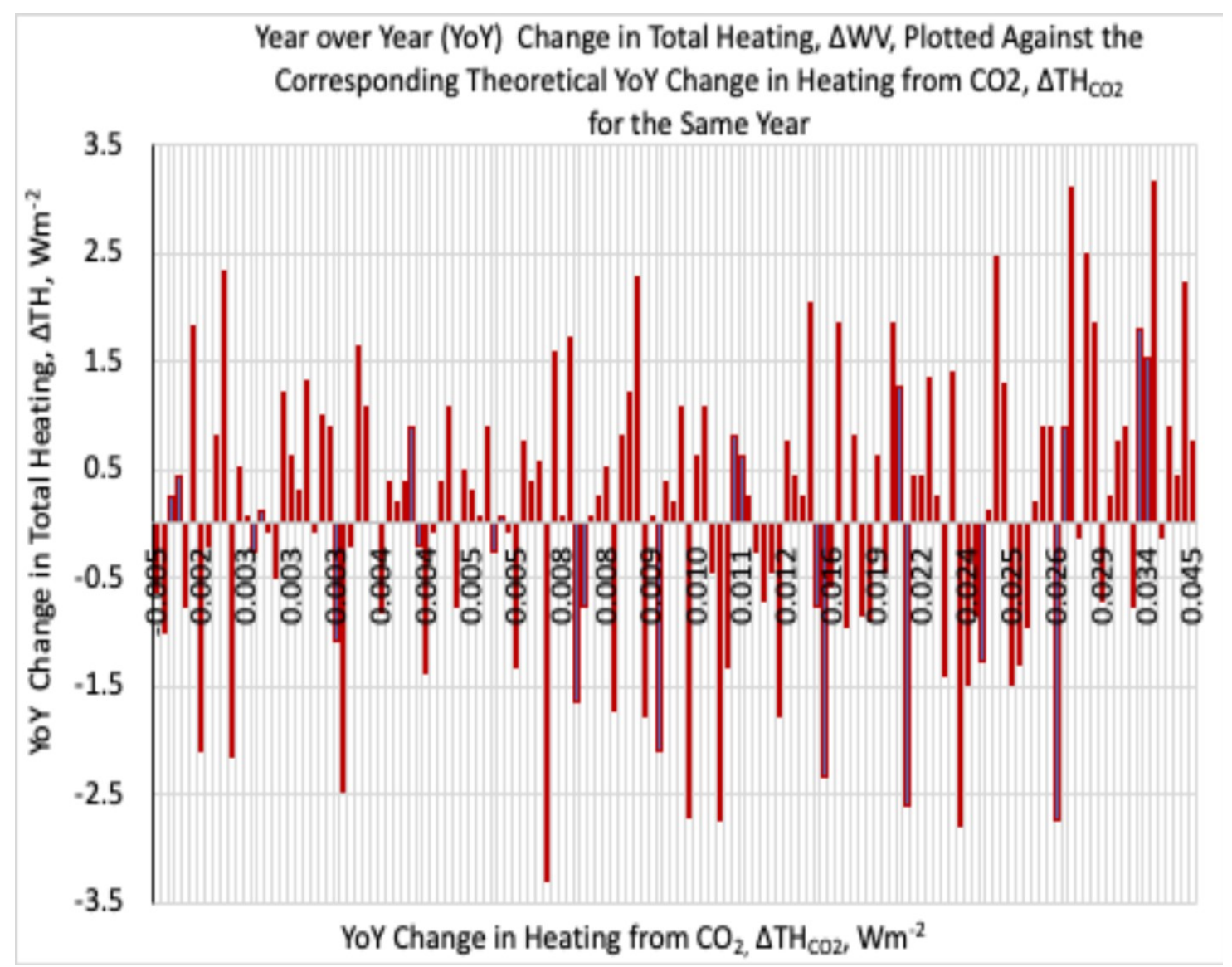

Figure 6. Year over Year Change in Total Heating, $\Delta$ TH Compared to the Corresponding YoY

Theoretical Change in Heating from $\mathrm{CO}_{2}, \Delta \mathrm{TH}_{\mathrm{CO} 2}$, for the Same Year

A YoY increase in heating from $\mathrm{CO}_{2}$ cannot drive an increase in heating as a feedback effect in one year and then in another year, a reduction in heating.

Those who make the assertion that $\mathrm{CO}_{2}$ drives global warming claim that increases in the concentration of water vapor are a feedback response to increases in heating from changes in the concentration of $\mathrm{CO}_{2}$ and these increases in the concentration of water vapor drive global warming. Therefore, it is asserted that $\mathrm{CO}_{2}$ is the driver, the forcing mechanism, required for global warming. 


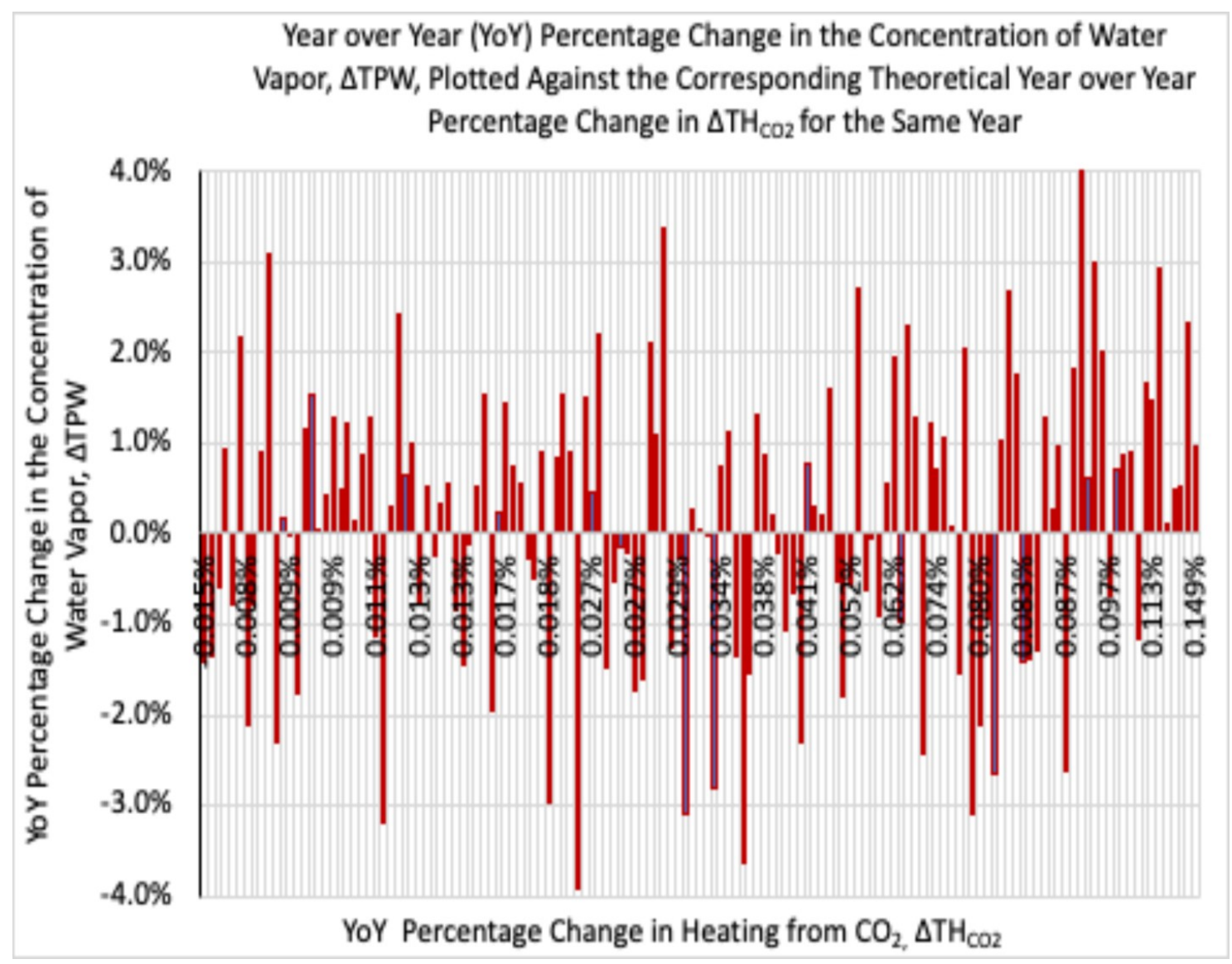

Figure 7. Year over Year Changes in the Concentration of Water Vapor, $\triangle T P W$, Compared to the Corresponding Year over Year Changes in Heating from $\mathrm{CO}_{2}, \Delta \mathrm{TH}_{\mathrm{CO} 2}$, for the Same Year

Here again, between 1880 and 2019, except for the period 1901-03, as the YoY theoretical heating from $\mathrm{CO}_{2}$ increased as shown in Figure 5, there is no correlation to the YoY changes in the concentration of water vapor, in fact $40 \%$ of the changes in the concentration of water vapor, $\triangle T P W$, were reductions. See Figure 7.

The same is true for changes in water vapor heating, $\Delta \mathrm{WV}$, of course, see Figure 8. 


\section{Year over Year Change in Water Vapor He Year over Year Change in $\Delta \mathrm{TH}_{\mathrm{CO} 2}$ for th}

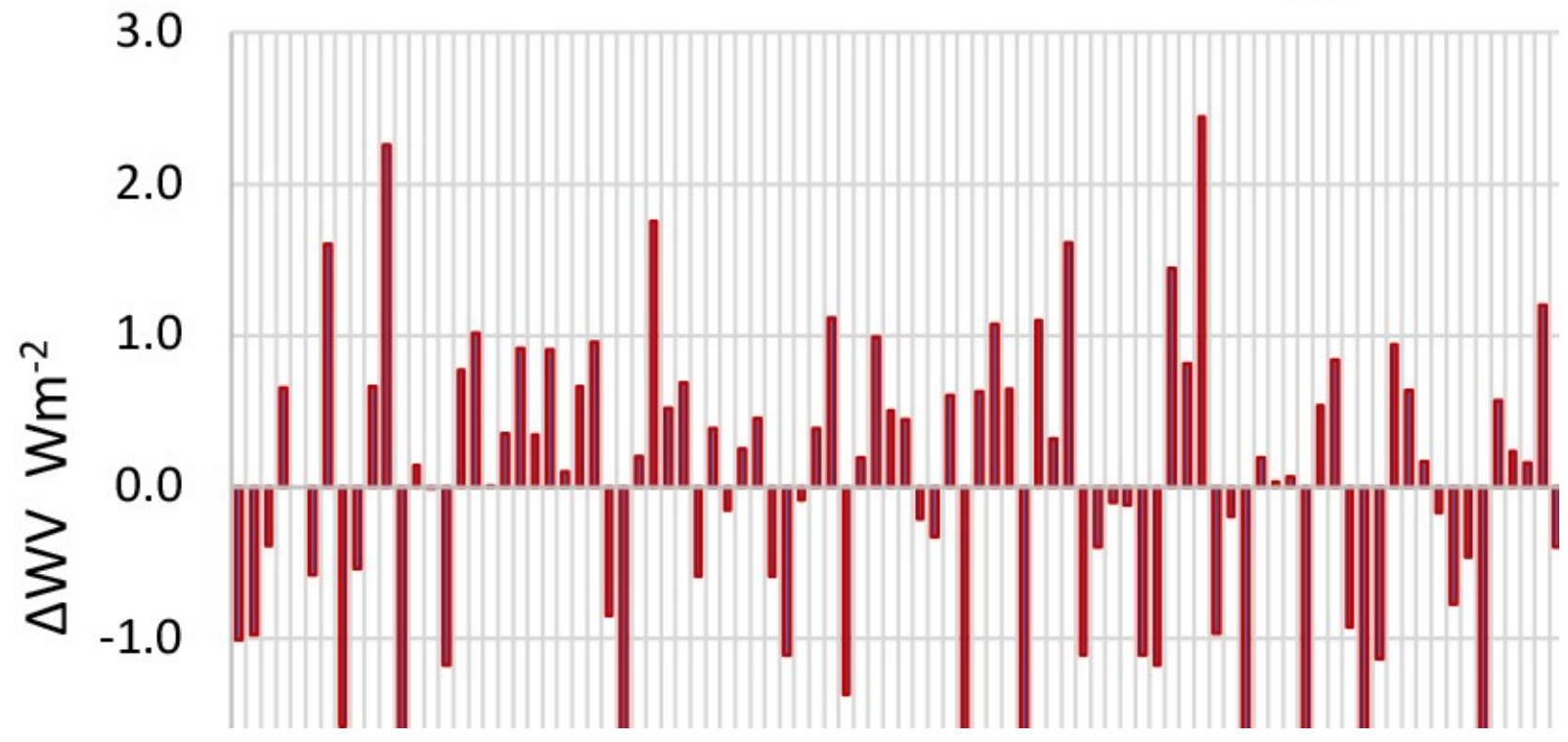

Figure 8. Year over Year Changes in Water Vapor Heating, $\Delta \mathrm{WV}$, Compared to Year over Year

Changes in Heating from $\mathrm{CO}_{2}, \Delta \mathrm{TH}_{\mathrm{CO} 2}$, for the Same Year

This is best illustrated in Figure 8 which is a plot of the YoY over year changes in water vapor heating compared to $\mathrm{YoY}$ changes in heating from $\mathrm{CO}_{2}$ for the same years with $\mathrm{YoY}$ changes in heating from $\mathrm{CO}_{2}, \Delta \mathrm{TH}_{\mathrm{CO} 2}$, shown increasing left to right on the horizontal axis.

A superficial examination of these changes clearly shows that there is no correlation between the theoretical changes in heating from $\mathrm{CO}_{2}$ and changes in water vapor heating. Like changes in total heating, changes in water vapor heating are autonomous, solely the result of changes in the concentration of water vapor resulting from differences between average evaporation and precipitation, and wholly unrelated to the theoretical changes in heating from $\mathrm{CO}_{2}$.

Given this, the reliance on carbon as a primary source of energy, the impact of deforestation, there being no practical means of reducing the concentration of $\mathrm{CO}_{2}$ in the atmosphere and the fact that just attempting to control global warming by limiting carbon emissions can impose annual societal costs of the order of one to five percent of the global GDP, why would the experimental solution to global warming be premised solely on the theory that carbon emissions from anthropogenic activities drive global warming?

If, notwithstanding the total lack of correlation between changes in the concentration of $\mathrm{CO}_{2}$ and changes in the concentration of water vapor, the belief, that by limiting $\mathrm{CO}_{2}$ emissions this would reduce the feedback effect and limit water vapor heating, is unchanged, why not also independently experiment with increasing precipitation and reducing the average concentration of water vapor 
directly?

\section{Conclusion}

The increasing concentration of $\mathrm{CO}_{2}$ is clearly not the cause of global warming. The cause is the increasing concentration of water vapor.

\section{Epilogue}

\section{When the Assumed Cause Is Not, the Problem Cannot be Solved}

Why should the single minded focus on $\mathrm{CO}_{2}$ put the world in such a position, especially when, even if, notwithstanding the science, one continued to believe that $\mathrm{CO}_{2}$ does play a role in heating, by driving increases in water vapor and water vapor heating, one should also believe that temperature reductions could still be achieved by the same means, reducing the concentration of water vapor by increasing precipitation?

The answer may not be solely science based (See, The Structure of Scientific Revolutions, in which Thomas Kuhn notes "Normal Science often Suppresses Fundamental Novelties").

If reducing the concentration of water vapor is not attempted, the final realization that the incredibly expensive experiment focused solely on $\mathrm{CO}_{2}$ failed will require substantial increases in temperature, which will take decades. At this point, the harm done could be massive and some damage may be irreversible. This is not, in any way, cogitable.

But this paper does highlight the solution, increasing global precipitation slightly can limit global warming. In fact, global warming can be reversed.

Please do not hesitate to share this but please understand that, even though I know that my work is sound and I have no connection to the fossil fuel industry or any agency of government, because this layman asserts, in effect, that the majority of the scientific community is wrong, most will view my work as incredible and heretical. However, I note that, before attending law school I earned a B.S. degree in Aeronautical Engineering from Penn State and while working full time for several years as a senior scientist in aerothermodynamics as part of a terrific R\&D team at Avco Missile Systems Division, on the Apollo command module and the design of probes into the planet Venus for NASA and reentry vehicles and other hypersonic systems for the Air Force and the Navy I received an M.S. degree from MIT in Aeronautics and Astronautics. In short, I have a firm grasp of the science underlying global warming-thermodynamics.

\section{APPENDIX}

\section{The Physics}

The new physical principles of atmospheric physics underlying this relationship are:

Change in the concentration of water vapor, $\triangle T P W$ 


$$
\Delta \mathrm{TPW}=\mathbf{0 . 1 5 7} \Delta \mathrm{TH}+17.53\left\{e^{[0.0686(\mathrm{SST} T+\Delta \mathrm{SST})-288)]}-e^{[0.0686(\mathrm{SST})-288)]}\right\} \mathrm{kgm}^{-2}
$$

Where $\mathrm{TH}$ is the average total solar and GHG heating, $\mathrm{Wm}^{-2}$; and, SST is the

global average sea surface temperature, $\mathrm{K}$

Change in water vapor heating, $\Delta W V$

$$
\Delta W V=73.3 \ln \left(1+\Delta T P W / T P W_{q}\right) \quad W^{-2}
$$

Change in the average global temperature, $\Delta \mathrm{T}_{\mathrm{Avg}}$

$$
\Delta T_{\text {Avg }}=0.4 \Delta \mathrm{TPW}^{\circ} \mathrm{C}
$$

